\title{
A Rare Case of Hyponatremia Caused by Reset Osmostat in a Neonate with Cleft Lip, Cleft Palate, and Imperforate
} Anus

\author{
Jung Gu Ahn, Jeong Eun Lee, Woo Yeong Chung, Soo Hyun Koo, Jaeho Shin*, and Ga Won Jeon \\ Department of Pediatrics, Division of Pediatric Surgery, Department of Surgery*, Inje University Busan Paik Hospital, Inje University \\ College of Medicine, Busan, Korea
}

\section{ABSTRACT}

Hyponatremia is defined as a plasma sodium concentration of $<135 \mathrm{mEq} / \mathrm{L}$. It is a common electrolyte imbalance in newborns. We report the case of a term neonate with cleft lip, cleft palate, imperforate anus, normal male karyotype, and chronic hyponatremia. On the 4th day of life, he showed hyponatremia (plasma sodium concentration $130 \mathrm{mEq} / \mathrm{L}$ ) with low serum osmolality (275 mOsm $/ \mathrm{kg})$, high urine sodium (116.7 mEq/L), and high urine osmolality (412 mOsm/kg). His thyroid and adrenal functions were normal. Despite intravenous and oral sodium supplementation and hydrocortisone treatment, hyponatremia persisted. Brain magnetic resonance imag. ing showed normal results. He was diagnosed as having reset osmostat, a rare subtype of the syndrome of inappropriate secretion of antidiuretic hormone characterized by a subnormal threshold for antidiuretic hormone secretion, with hypotonic hyponatremia.

Key Words: Hyponatremia, Inappropriate ADH syndrome, Newborn, Cleft palate, Imperforate anus

\section{INTRODUCTION}

Hyponatremia is one of the most common electrolyte disturbances, reported in up to $25 \%$ to $65 \%$ of the ill newborns in the neonatal intensive care units ${ }^{1)}$. It is defined as a plasma sodium concentration of $<135 \mathrm{mEq} / \mathrm{L}^{2)}$. Hyponatremia in neonates usually develops owing to the inability of the immature neonatal kidney to excrete excess water. Hypotonic hyponatremia with a serum osmolality of $<280 \mathrm{mOsm} / \mathrm{kg}$ is relatively common in newborns. It can be clinically classified into three types according to the extracellular volume status. Hypovolemic hyponatremia occurs when the sodium loss exceeds the water loss. Renal loss or extrarenal loss (e.g., gastrointestinal loss, 3rd space loss, and skin loss) of sodium can cause this condition. Hypervolemic hyponatremia is caused by water accumulation in excess of the sodium intake. Euvolemic hyponatremia occurs secondary to hypothyroidism,
Received: 8 June 2018

Revised: 11 August 2018

Accepted: 13 August 2018

Correspondence to: Ga Won Jeon

Department of Pediatrics, Inje University Busan Paik Hospital, Inje University College of Medicine, 75 Bokjiro, Busanjin-gu, Busan 47392, Korea

Tel: +82-51-890-6497

Fax: +82-51-895-7785

E-mail: iamgawon@paik.ac.kr

Copyright(c)

By Korean Society of Neonatology.

All right reserved.

This is an Open-Access article distributed under the terms of the Creative Commons Attribution Non-Commercial License (http://creativecommons.org/licenses/ by-nc/4.0), which permits unrestricted non-commercial use, distribution, and reproduction in any medium, provided the original work is properly cited. 
glucocorticoid deficiency, or syndrome of inappropriate antidiuretic hormone (SIADH). About $60 \%$ of the patients with chronic euvolemic hyponatremia have SIADH, which is the most common cause of euvolemic hyponatremia ${ }^{2)}$. In 1967, Bartter and Schwartz ${ }^{3)}$ described the cardinal criteria of SIADH, as follows: (1) hyponatremia with hypo-osmolality of the serum and extracellular fluid; (2) continuous sodium excretion by the kidney; (3) absence of volume depletion, meaning normal skin turgor and blood pressure; (4) urine osmolality greater than plasma osmolality, meaning inappropriate urine concentration; (5) normal renal function; and (6) normal adrenal function. An elevated concentration of plasma arginine vasopressin (AVP), one of the main antidiuretic hormones (ADHs), is essential in the development of SIADH, independent of primary or secondary elevation. The measurement of plasma AVP concentration is not helpful in diagnosing SIADH because many other conditions of hyponatremia are associated with the secondary elevation of AVP concentration ${ }^{2}$.

In most cases, SIADH in neonates is caused by central nervous system infection and brain injury; however, in some rare cases, SIADH may be caused by reset osmostat. The diagnostic criteria for reset osmostat include euvolemia, normal renal, adrenal, and thyroid functions, ability to concentrate the urine and excrete the overloaded fluid, and hyponatremia despite salt overload ${ }^{4)}$. Here, we report a case of a newborn with refractory hyponatremia secondary to reset osmostat, a rare type of SIADH.

\section{CASE REPORT}

A male infant was born as small for gestational age at 37 weeks and 4 days of gestation via a vaginal delivery. Both his parents were 24 years old. He was the 5th child of his mother (of Korean ethnicity) and has no parental consanguinity. He was the 1st baby of his father. His mother was phenotypically normal. His father had midface hypoplasia. His father had undergone a correction operation for cleft lip and palate when he was young. His mother had a history of smoking five cigarettes per day. She did not take any drug during the pregnancy. Prenatal ultrasonography detected bilateral hydronephrosis and facial dysmorphism including a flat face, cleft lip, and cleft palate with normal fetal movement.

The patient's Apgar scores were 8 and 9 at 1 and 5 minutes, respectively. He weighed 2,500 g (3rd to 10th percentile) and was $47 \mathrm{~cm}$ long (10th to 25th percentile) with a head circumference of $30.5 \mathrm{~cm}$ (3rd to 10th percentile). He had brachycephaly, a short anteroposterior diameter, midface hypoplasia with hypertelorism, small nose, low nasal bridge, flat occiput, maxillary hypoplasia, cleft lip, cleft palate (Figure 1), and low-type imperforate anus with fistula (Figure 2). Echocardiography showed a patent ductus arteriosus and an atrial septal defect. Sacral ultrasound showed normal results. Renal ultrasound revealed bilateral hydronephrosis.

On the 5th day of life, the baby underwent an anoplasty. He passed normal stool within 24 hours after the operation. He was able to take milk. His plasma sodium concentration started to decrease from the 4 th day of life. Thereafter, he had hyponatremia

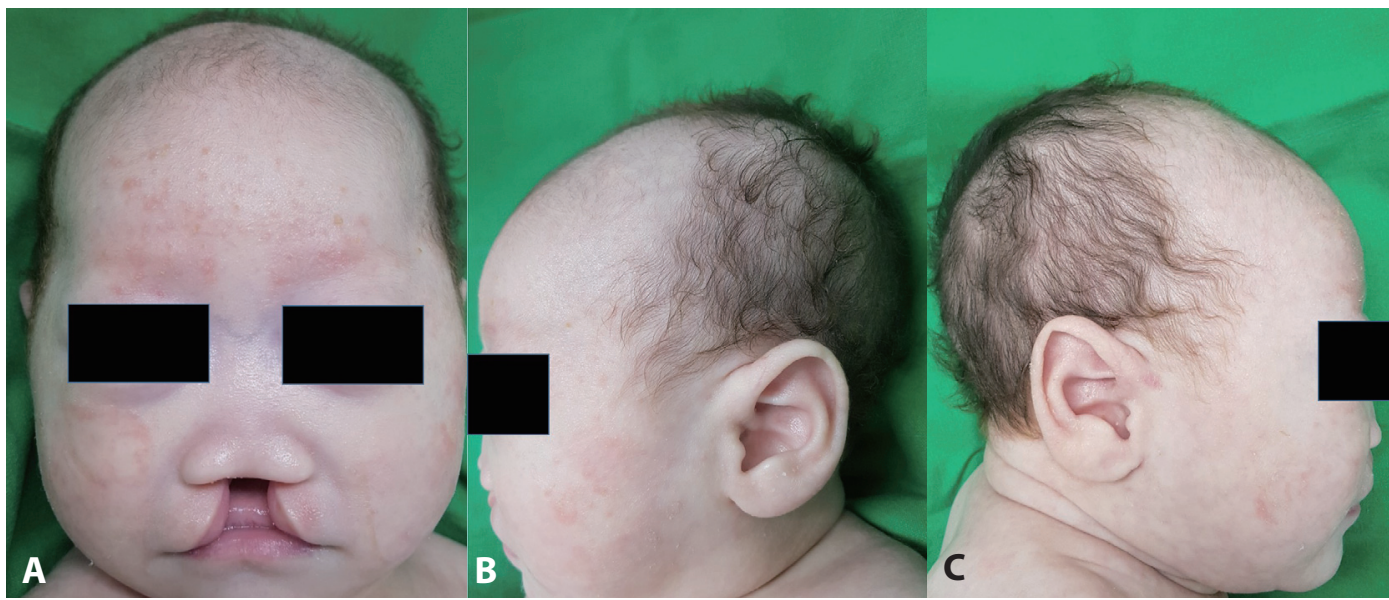

Figure 1. Photographs of the face. (A) Hypertelorism, maxillary hypoplasia, low nasal bridge, and cleft lip and palate. (B, C) Short anteroposterior diameter with a flat occiput. 
with sodium concentration maintained at $130 \mathrm{mEq} / \mathrm{L}$. It was neither caused by volume overloading during anoplasty nor by the inability of the immature kidney to excrete free water. He

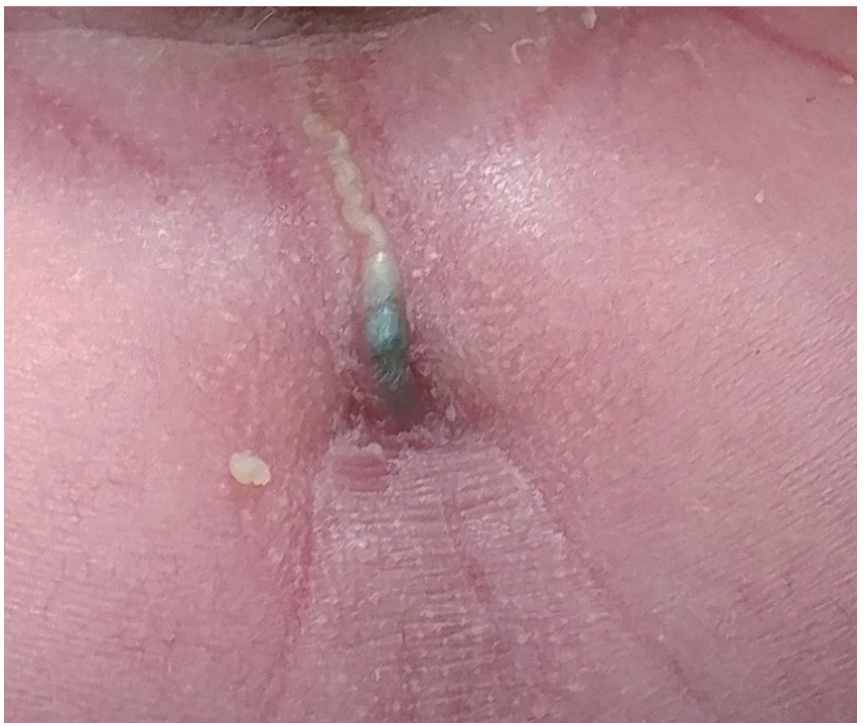

Figure 2. Photographs of the anus. Imperforate anus with lowtype anocutaneous fistula. showed low plasma sodium concentration (125 mEq/L), low serum osmolality ( $275 \mathrm{mOsm} / \mathrm{kg}$ ), high urine sodium concentration (116.7 mEq/L), and high urine osmolality (412 mOsm/kg). Further tests performed, including glucose, blood urea nitrogen, creatinine, uric acid, and urinalysis, showed normal results. Endocrinologic assessments for adrenocorticotropic hormone, cortisol, aldosterone, parathyroid hormone, triiodothyronine, free thyroxine, and thyroid-stimulating hormone also yielded normal findings. Brain magnetic resonance imaging showed normal pituitary gland and hypothalamus. Chromosomal analysis showed normal male karyotype, after obtaining informed consent.

Daily intravenous sodium replacement ( 5 to $8 \mathrm{mEq} / \mathrm{kg}$ ) was given from the 5th postnatal day. However, hyponatremia persisted. Hydrocortisone ( $1 \mathrm{mg} / \mathrm{kg}$ ) was injected daily from the 13th postnatal day until adrenal insufficiency was excluded. However, hyponatremia persisted. Intravenous hypertonic sodium replacement ( $6 \mathrm{mEq} / \mathrm{kg}$ ) was administered from the 19th postnatal day (Table 1). Despite sodium replacement and hydrocortisone treat ment with volume restriction to $120 \mathrm{~mL} / \mathrm{kg}$, his sodium concentration remained low, between 125 and 128

Table 1. Daily Weight, Input, Output, Sodium Concentration, and Treatment

\begin{tabular}{|c|c|c|c|c|c|c|c|c|}
\hline $\begin{array}{l}\text { Postnatal } \\
\text { day } \\
\text { (day) }\end{array}$ & $\begin{array}{c}\text { Weight } \\
\text { (kg) }\end{array}$ & $\begin{array}{c}\text { Input } \\
(\mathrm{mL} / \mathrm{kg} / \text { day })\end{array}$ & $\begin{array}{l}\text { Urine output } \\
(\mathrm{mL} / \mathrm{kg} / \mathrm{hr})\end{array}$ & $\begin{array}{c}\text { Serum Na } \\
(\mathrm{mEq} / \mathrm{L})\end{array}$ & $\begin{array}{c}\text { Serum } \\
\text { osmolality } \\
\text { (mOsm/kg) }\end{array}$ & $\begin{array}{l}\text { Urine Na } \\
(\mathrm{mEq} / \mathrm{L})\end{array}$ & $\begin{array}{c}\text { Urine } \\
\text { osmolality } \\
\text { (mOsm/kg) }\end{array}$ & Treatment \\
\hline 1 & 2.50 & 60 & 0.5 & 139 & & & & \\
\hline 4 & 2.52 & 71 & 2.7 & 130 & & & & Na replace (2 mEq/kg, iv) \\
\hline \multirow[t]{2}{*}{5} & 2.42 & 110 & 2.5 & 127 & & & & Na replace (5 mEq/kg, iv) \\
\hline & & & & & & & & Anoplasty \\
\hline $13^{*}$ & 2.65 & 130 & 3.2 & 125 & 412 & 116.7 & 275 & Hydrocortisone (1 mg/kg) \\
\hline \multirow[t]{2}{*}{19} & 2.65 & 124 & 2.6 & 127 & & & 275 & Hydrocortisone stop \\
\hline & & & & & & & & Hypertonic saline ( $6 \mathrm{mEq} / \mathrm{kg}$, iv) \\
\hline 20 & 2.70 & 115 & 3.3 & 128 & & & & Hypertonic saline (6mEq/kg, iv) \\
\hline 22 & 2.71 & 115 & 2.8 & 129 & 161 & 54 & 267 & Hypertonic saline ( $6 \mathrm{mEq} / \mathrm{kg}$, iv) \\
\hline \multirow[t]{2}{*}{$40^{\dagger}$} & 3.26 & 156 & 4.2 & 128 & 246 & 33 & 269 & Furosemide (2 mg/kg) \\
\hline & & & & & & & & Na replace $(5 \mathrm{mEq} / \mathrm{kg}$, oral) \\
\hline \multirow[t]{2}{*}{48} & 3.58 & 150 & 3.2 & 131 & 229 & 75.3 & 272 & Furosemide (2 mg/kg) \\
\hline & & & & & & & & Na replace $(5 \mathrm{mEq} / \mathrm{kg}$, oral) \\
\hline \multirow[t]{2}{*}{60} & 4.10 & & & 128 & & & & Furosemide stop \\
\hline & & & & & & & & Na replace ( $5 \mathrm{mEq} / \mathrm{kg}$, oral) \\
\hline
\end{tabular}

*Postnatal day 13: Serum concentration was determined before hydrocortisone treatment; ${ }^{\dagger}$ Postnatal day 40: Serum concentration was determined before furosemide treatment. Abbreviation: iv, intravenous. 
$\mathrm{mEq} / \mathrm{L}$. We started oral supplementation of sodium from 2.5 to 5 $\mathrm{mEq} / \mathrm{kg}$ from the 25 th postnatal day. His sodium concentration increased to $131 \mathrm{mEq} / \mathrm{L}$, which was still low. However, it did not decrease to $<128 \mathrm{mEq} / \mathrm{L}$. We added sodium in the milk four times per day. Treatment with furosemide from the 40th postnatal day to induce excretion of free water was not effective in increasing his sodium concentration. Thus, we stopped furosemide on the 60th postnatal day at the outpatient clinic. His plasma sodium concentration ranged from 128 to $131 \mathrm{mEq} /$ $\mathrm{L}$ and serum osmolality was 267 to $272 \mathrm{mOsm} / \mathrm{kg}$. His urine sodium concentration was 18 to $75 \mathrm{mEq} / \mathrm{L}$ and urine osmolality was 127 to $246 \mathrm{mOsm} / \mathrm{kg}$. Both urine sodium concentration and urine osmolality increased after the oral supplementation of sodium. He was fed well, with the use of a Haberman feeder because of his cleft lip and cleft palate. His weight gain was good after supplementation with sodium and sufficient calories ( $>90$ $\mathrm{kcal} / \mathrm{kg}$ ) after the 7 th day of birth. He was discharged from the neonatal intensive care unit on the 54th day of life with a sodium concentration of $131 \mathrm{mEq} / \mathrm{L}$. He was clinically well with normal growth and development, including head control, pursuit eye movements, babbling, and smiling in response to face and voice. He did not show any kind of seizures due to hyponatremia. We continued to supply oral sodium ( $5 \mathrm{mEq} / \mathrm{kg}$ ) and monitor his plasma sodium concentration, growth, and development.

\section{DISCUSSION}

Hyponatremia is believed to be a benign disease; however, it is a very common condition in newborn babies. Euvolemic hyponatremia usually occurs secondary to hypothyroidism, gluco. corticoid deficiency, or increased ADH concentration ${ }^{5)}$. Sodium is a crucial element for growth and weight gain. It is present in the bone, cartilage, and connective tissues. Sodium is also essential for the development of the brain and the central nervous system. Researchers have reported that preterm infants with chronic hyponatremia experience delayed development and poor growth ${ }^{1,4,6-8)}$. Preterm infants with chronic hyponatremia associated with sodium-restricted diets show impaired development of body physique and poor neurodevelopmental outcomes at school ages, compared with preterm infants with normal sodium concentration associated with sodium-supplemented $\operatorname{diets}^{7}$.

Reset osmostat is one of the four subtypes of SIADH, based on $\mathrm{ADH}$ secretion. Type $\mathrm{A}$ is characterized by high and erratic fluctuation in the concentration of $\mathrm{ADH}$ that is not physiologically affected by serum osmolality. Type B is defined as modest and constant leakage of $\mathrm{ADH}$. Type $\mathrm{C}$ is defined as reset osmostatinduced excretion of $\mathrm{ADH}$ caused by a decrease in the plasma osmolality threshold. Plasma sodium adjusted to a lower concentration between 125 and $135 \mathrm{mEq} / \mathrm{L}$. Type $\mathrm{D}$ is characterized by normal osmoregulation of $\mathrm{ADH}$ with upregulation of vasopressin receptor 2 expression without $\mathrm{ADH}$ elevation ${ }^{4)}$. According to the diagnostic criteria, normal renal, adrenal, and thyroid functions, normal capacity to concentrate urine and excrete overloaded fluid, and hyponatremia despite salt replacement should be present to diagnose reset osmostat euvolemia ${ }^{4)}$.

Babies who experience fetal distress, a difficult delivery, or perinatal/neonatal asphyxia secondarily develop elevated cir culating $\mathrm{ADH}$ concentrations, compared with babies born un eventfully. However, true SIADH with primary elevation of $\mathrm{ADH}$ is relatively rare in the newborn period. The diagnosis of SIADH should be made according to the diagnostic criteria, including normal blood pressure and normal adrenal, thyroid, renal, and cardiac functions ${ }^{9)}$. In most cases, the duration of hyponatremia caused by SIADH is $<3$ days. Chronic SIADH persisting for $>3$ days is rare in children, and only 15 cases have been reported. The incidence of SIADH in newborns is unknown owing to its extreme rarity ${ }^{5}$.

Some rare cases of SIADH caused by reset osmostat have been reported in newborns. A case of reset osmostat in a male preterm infant (36 weeks of gestational age, with cleft lip and palate at prenatal ultrasonography) has been reported. The infant showed hyponatremia (plasma sodium concentration $131 \mathrm{mEq} / \mathrm{L}$ ) on the 7 th day of life ${ }^{4)}$. Despite fludrocortisone and oral sodium replacement, his plasma sodium concentration was maintained between 124 and $130 \mathrm{mEq} / \mathrm{L}$. At 16 to 19 months of age, he showed progressive growth restriction and mild delay in development ${ }^{4)}$. Another case of reset osmostat was reported in a female preterm infant at 36 weeks of gestational age, with cleft lip and cleft palate at prenatal ultrasonography, showing panhypopituitarism with normal brain structure and hyponatre mia (plasma sodium concentration between 124 and $130 \mathrm{mEq} /$ L) from the 1st postnatal day ${ }^{6)}$. Her hyponatremia persisted despite replacement of hydrocortisone with fludrocortisone and oral sodium. At 15 months of age, she showed growth restriction with mild delay in development ${ }^{6)}$. A case of reset osmostat was also reported in a female term infant with a dysmorphic face. She presented with midface hypoplasia with hypertelorism, small 
nose and mouth, choanal atresia, maxillary hypoplasia, and high-arched palate. She showed a chromosomal abnormality with unbalanced translocation between chromosome 13 and chromosome $\mathrm{X}$, resulting in $46, \mathrm{X},-\mathrm{X},+\operatorname{der}(\mathrm{X}) \mathrm{t}(\mathrm{X}$; 13) (p22.1; q22). Hyponatremia persisted (plasma sodium concentration between 127 and $133 \mathrm{mEq} / \mathrm{L}$ ) despite intravenous/oral sodium replacement and glucocorticoid therapy. At 7 months of age, she showed growth restriction with diminished growth velocity and delayed development, including delayed language, motor, and cognitive functions ${ }^{8)}$.

There is no clear consensus about the treatment of hyponatremia. The treatment and outcomes have been variable. Thus, treatment varies from water restriction to administration of demeclocycline, lithium, furosemide, and AVP antagonists, such as urea, for observation without any treatment ${ }^{10)}$. In our case, intravenous sodium supplementation and hydrocortisone treatment were not effective; after treatment, the plasma sodium concentration ranged between 127 and $129 \mathrm{mEq} / \mathrm{L}$. Furosemide causes overflow to the concentrating areas of the nephron, which overwhelms the normal transport capacity independent of the baseline water permeability, thus, inducing free water clearance. Thus, we started to use furosemide. Oral supplementation with sodium and oral furosemide treatment were continued at the outpatient department. Since the plasma sodium concentration was between 128 and $131 \mathrm{mEq} / \mathrm{L}$ despite oral sodium and furoemide treatment, furosemide was stopped. Furosemide and hydrocortisone treatment did not lower the baseline serum sodium concentration compared with oral sodium supplementation only, and furosemide did not increase the urine sodium concen tration.

There have been some reported cases of reset osmostat in newborn babies with cleft lip and palate, or a high-arched palate. Thus, clinicians who treat babies with chronic hyponatremia should suspect reset osmostat especially in babies with cleft lip and palate or a high-arched palate. Patients with chronic hyponatremia caused by reset osmostat need specific treatment, including sodium replacement to prevent developmental delay and growth restriction.

\section{CONFLICT OF INTEREST}

No potential conflict of interest relevant to this article was reported.

\section{REFERENCES}

1. Marcialis MA, Dessi A, Pintus MC, Irmesi R, Fanos V. Neonatal hyponatremia: differential diagnosis and treatment. J Matern Fetal Neonatal Med 2011;24 Suppl 1:75-9.

2. Baylis $\mathrm{PH}$. The syndrome of inappropriate antidiuretic hormone secretion. Int J Biochem Cell Biol 2003;35:1495-9.

3. Bartter FC, Schwartz WB. The syndrome of inappropriate secretion of antidiuretic hormone. Am J Med 1967;42:790-806.

4. Vale BM, Morais S, Mesquita J, Mimoso G. Reset osmostat: a rare cause of hyponatraemia. BMJ Case Rep 2015;2015: bcr2013009111.

5. Marcialis MA, Dessi A, Contu S, Fanos V. Nephrogenic syndrome of inappropriate antidiuresis: a novel cause of euvolemic hypotonic hyponatremia in newborns. Diagnosis and practical management. J Matern Fetal Neonatal Med 2009;22 Suppl 3:6771.

6. Thiagarajan R, La Gamma E, Dey S, Blethen S, Wilson TA. Hyponatremia caused by a reset osmostat in a neonate with cleft lip and palate and panhypopituitarism. J Pediatr 1996;128:5613.

7. Moritz ML, Ayus JC. Hyponatremia in preterm neonates: not a benign condition. Pediatrics 2009;124:e1014-6.

8. Gupta P, Mick G, Fong CT, Jospe N, McCormick K. Hyponatre mia secondary to reset osmostat in a child with a central nervous system midline defect and a chromosomal abnormality. J Pediatr Endocrinol Metab 2000;13:1637-41.

9. Modi N. Hyponatraemia in the newborn. Arch Dis Child Fetal Neonatal Ed 1998;78:F81-4.

10. Chehade H, Rosato L, Girardin E, Cachat F. Inappropriate antidiuretic hormone secretion: long-term successful urea treatment. Acta Paediatr 2012;101:e39-42. 